\title{
De novo transcriptome analysis of tobacco seedlings and identification of the early response gene network under low-potassium stress
}

\author{
L.Q. Li, J. Li, Y. Chen, Y.F. Lu and L.M. Lu \\ College of Agronomy, Sichuan Agricultural University, Chengdu, China \\ Corresponding author: L.M. Lu \\ E-mail: louis_luliming@126.com
}

Genet. Mol. Res. 15 (3): gmr.15038599

Received March 2, 2016

Accepted April 15, 2016

Published August 18, 2016

DOI http://dx.doi.org/10.4238/gmr.15038599

Copyright (C 2016 The Authors. This is an open-access article distributed under the terms of the Creative Commons Attribution ShareAlike (CC BY-SA) 4.0 License.

\begin{abstract}
Tobacco is an economically important crop, and its potassium content can greatly affect the quality of tobacco leaves. However, the molecular mechanism involved in potassium starvation in tobacco has not been elucidated to date. In this study, Illumina (Solexa) sequencing technology was used to analyze the transcriptome of tobacco seedlings under low-potassium stress for 6, 12, and $24 \mathrm{~h}$. After analysis, 107,824 assembled unigenes were categorized into $57 \mathrm{GO}$ functional groups, and 31,379 unigenes $(29.08 \%)$ were clustered into 25 COG categories. A total of 9945 genes were classified into $233 \mathrm{KEGG}$ pathways, and 15,209 SSRs were found among the 107,824 unigenes. Between the two samples, 1034 genes were differentially expressed. Twelve randomly selected gene expression levels were analyzed by quantitative RT-PCR, and the results were highly consistent with those
\end{abstract}

Genetics and Molecular Research 15 (3): gmr.15038599 
obtained by Solexa sequencing. Our results provide a comprehensive analysis of the gene-regulatory network of tobacco seedlings under low-potassium stress.

Key words: Tobacco; Potassium deficiency; Gene expression; Illumina sequencing technology; Transcriptome

\section{INTRODUCTION}

Potassium $\left(\mathrm{K}^{+}\right)$plays a major role in plant growth, development, and response to stress. Generally, the $\mathrm{K}^{+}$concentration in the soil is within the range of 0.025 to $5 \mathrm{mM}$; however, the cytoplasmic $\mathrm{K}^{+}$concentration in plant cells is approximately $100 \mathrm{mM}$. Due to the limited availability of $\mathrm{K}^{+}$in the soil, most plants have evolved both high- and low-affinity $\mathrm{K}^{+}$ transport systems (Ward et al., 2009); in particular, high-affinity $\mathrm{K}^{+}$transporters function to allow survival under $\mathrm{K}^{+}$deficiency stress (Very and Sentenac, 2003). For example, AtHAK5, OsHAK1, and TaAKT1 (Buschmann et al., 2000; Bañuelos et al., 2002; Gierth et al., 2005) were induced by $\mathrm{K}^{+}$starvation. Recent studies suggested that calcium-mediated CBL-CIPK signaling could regulate the $\mathrm{K}^{+}$channels AKT1 and ATK2 in Arabidopsis (Xu et al., 2006; Held et al., 2011). These results imply that plants have formed a complex signaling and molecular regulatory network to adapt to $\mathrm{K}^{+}$-deficient environments.

Tobacco is an economically important crop that is used as a model plant in gene function research. China is one of the main tobacco-producing countries. In recent years, following increased consumption, the quality requirements for tobacco have also increased. The potassium content has become one of the important indices to evaluate the quality of tobacco leaves (Chaplin, 1980). Additionally, the potassium content correlates with the safety of tobacco leaves; research suggests that tobacco leaves with 1-5\% more potassium can reduce the tar content by $20 \%$ (Yamamoto et al., 1990). Improving the potassium content of tobacco has become an important focus of tobacco research. Recently, transcriptomic analyses have been widely adopted in functional genomic studies of both model and nonmodel plants. Lu et al. (2015) performed a transcriptomic analysis of tobacco seedlings that were subjected to a low potassium treatment using the gene chip method. Now, the next-generation sequencing method RNA-seq can provide a large amount of expressed sequence tags and transcript expression information between samples (Vanverk et al., 2013). This technique has been applied in studies of plant responses to various abiotic stressors (Postnikova et al., 2013; Zeng et al., 2014).

In this study, two complementary DNA (cDNA) libraries were generated from tobacco seedlings grown on MS medium and under low-potassium stress for 6, 12, and $24 \mathrm{~h}$. The Illumina (Solexa) sequencing platform was used for the de novo transcriptome sequencing of the two library samples. After analysis, 1034 unigenes were differentially expressed by at least 2-fold. A total of 12 unigenes were randomly selected, and their expression levels were confirmed by quantitative real-time polymerase chain reaction (qRT-PCR). The results suggested that the RNA-seq data were strongly correlated with the qRT-PCR data. The aims of this study were to discover the molecular basis of the tobacco seedling's early response to low-potassium stress and to serve as a valuable resource for future research on potassium stress.

Genetics and Molecular Research 15 (3): gmr.15038599 


\section{MATERIAL AND METHODS}

\section{Plant materials and growth conditions}

Tobacco seeds were surface sterilized and germinated on MS medium for 20 days. The greenhouse was maintained under a $16-\mathrm{h} / 8$-h day/night light cycle and a $28^{\circ} / 25^{\circ} \mathrm{C}$ day/ night temperature cycle. Then, the seedlings were transferred to low-potassium medium for 6 , 12, and $24 \mathrm{~h}$ of treatment. Seedlings grown on MS medium served as a control. Two seedling samples were collected, immediately frozen in liquid nitrogen, and then stored at $-80^{\circ} \mathrm{C}$ for further analysis. The normal MS medium contained $0.8 \%(\mathrm{w} / \mathrm{v})$ agarose and $3 \%(\mathrm{w} / \mathrm{v})$ sucrose. The LK medium was modified from MS medium (Liu et al., 2013).

\section{Construction of the cDNA library for sequencing}

Total RNA was isolated from tobacco seedlings using TRIzol reagent (Invitrogen, USA) following the manufacturer protocol. RNA quality and concentration was checked using an Agilent Bioanalyzer 2100 (Agilent Technologies, USA). Poly(A) mRNA was isolated using an Oligotex mRNA Mini Kit (QIAGEN, Germany) from the total RNA quantified and then broken into short fragments for cDNA library construction. Two tobacco seedling cDNA libraries were constructed using the Genomic DNA Sample Prep Kit (Illumina, USA) according to the manufacturer protocol. Paired-end transcriptome sequencing was performed by Shanghai Biotechnology Corporation (Shanghai, China) using an Illumina $\mathrm{HiSeq}^{\mathrm{TM}} 2000$.

\section{De novo assembly and functional annotation of unigenes}

CLC Genomics Workbench (version 4.9; QIAGEN) was used to pre-process and assemble the raw sequence data. Before assembly, the adapter sequences, low-quality $(\mathrm{Q} 20,20)$ sequences, and ambiguous inner regions were removed. A contig scaffolding algorithm was used for de novo assembly, length fraction, and similarity ratio, and the minimum contig parameters were considered. The function of unigenes was annotated by a BLASTx against the NCBI non-redundant $(\mathrm{Nr})$ database, with a typical cut-off E-value of $10^{-5}$. WEGO was used to perform a Gene Ontology (GO) classification (Ye et al., 2006). The unigene sequences were aligned to the Clusters of Orthologous Groups (COG) database and Kyoto Encyclopedia of Genes and Genomes (KEGG) database to predict and classify gene functions.

\section{Identification and functional annotation of differentially expressed genes (DEGs)}

In this study, the expression level of each transcript was analyzed between the two samples using the RPKM method (reads per kilobase of transcript per million mapped reads) (Mortazavi et al., 2008). The significance of the difference in gene expression between the control (CK) and low-potassium (LK) treatment was determined using DEGseq, an R package (Wang et al., 2010). When the false-discovery rate was less than 0.05 and the $\log _{2}$ ratio was greater than 1 (2-fold change) between the two samples, the unigenes were considered differentially expressed.

Genetics and Molecular Research 15 (3): gmr.15038599 


\section{qRT-PCR analysis}

Based on the target gene sequences, 12 gene-specific primer pairs were designed with the Premier 5.0 software (PREMIER Biosoft, USA). qRT-PCR was performed in a $25-\mu \mathrm{L}$ reaction volume that included $1 \mu \mathrm{L}$ cDNA, $12.5 \mu \mathrm{L}$ 2X SYBR Green Master Mix, and $10 \mu \mathrm{M}$ forward and reverse primers. Three biological replicates were performed in each experiment. The thermal cycling conditions were as follows: $95^{\circ} \mathrm{C}$ for $10 \mathrm{~s}, 95^{\circ} \mathrm{C}$ for $15 \mathrm{~s}$, and $50^{\circ} \mathrm{C}$ for $1 \mathrm{~min}$ for a total of 40 cycles. The tobacco actin gene was used as an internal control for normalization to compare the gene expression level. The relative gene expression levels were calculated using the $2^{-\Delta \Delta \mathrm{Ct}}$ method.

\section{RESULTS}

\section{Sequencing and de novo transcriptome assembly}

Two cDNA libraries were constructed from the CK and LK treatments of tobacco seedlings. After sequencing, 60,637,384 raw reads were generated from the CK library, and 49,037,982 raw reads were generated from the LK library. The raw data was deposited in the Gene Expression Omnibus (GEO) database (Accession Nos. GSM1555574 and GSM1555575). The raw reads had an average length of $100 \mathrm{bp}$. Clean reads from the CK and LK samples were $57,448,884$ and 46,640,789 bp, respectively, after removing the low-quality reads and adapter sequences. After de novo assembly, 107,824 unigenes were acquired; the average unigene length was $795 \mathrm{bp}$, and the N50 was $962 \mathrm{bp}$ (Table 1).

Table 1. Summary of sequencing and assembly results.

\begin{tabular}{l|c|c|c|c|c|c}
\hline Item & Library & Number (N) & Sequence (bp) & Average length (bp) & N50 (bp) & Maximum (bp) \\
\hline Raw read & CK & $60,637,384$ & $6,063,738,400$ & 100 & - & - \\
\hline & LK & $49,037,982$ & $4,903,798,200$ & 100 & - & - \\
\hline Clean read & CK & $57,448,884$ & $5,371,470,654$ & 93.5 & - & - \\
\hline & LK & $46,640,789$ & $4,309,608,904$ & 92.4 & - & - \\
\hline Total & Contig & 167,260 & $82,973,380$ & 555 & 710 & 13,178 \\
\hline & Unigene & 107,824 & $85,772,965$ & 795 & 962 & 13,178 \\
\hline
\end{tabular}

\section{Functional annotation}

All 107,824 assembled unigenes were blasted against the NCBI Nr protein database using a cut-off E-value of $10^{-5}$. In total, 55,926 unigenes (51.9\%) were annotated. For the E-value distribution, $55.6 \%$ had an E-value of less than $1.0 \mathrm{E}^{-50}$, whereas the remaining $44.4 \%$ had an E-value between $1.0 \mathrm{E}^{-5}$ and $1.0 \mathrm{E}^{-50}$. The similarity distribution showed that $30.76 \%$ of these aligned unigenes had a similarity higher than $90 \%$. Regarding species distribution, Vitis vinifera $(32.75 \%)$ was the most closely matched species, followed by Ricinus communis (11.72\%), Populus trichocarpa (11.34\%), Nicotiana tabacum (7.22\%), Glycine max (6.16\%), Solanum lycopersicum (4.46\%), and S. tuberosum (2.88\%). The 20 top-hit species based on the $\mathrm{Nr}$ annotation are shown in Figure 1.

Genetics and Molecular Research 15 (3): gmr.15038599 

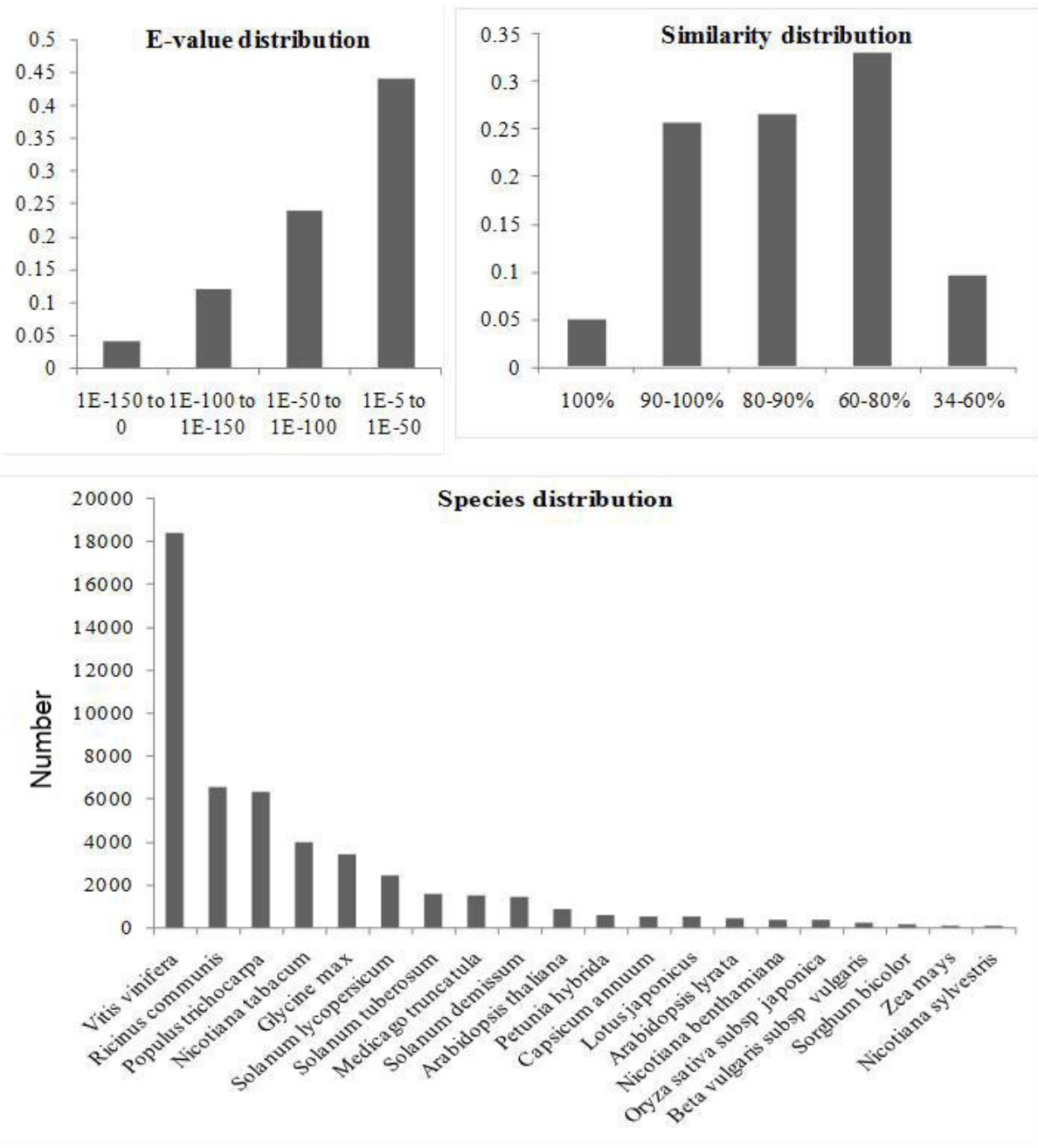

Figure 1. Characteristics of a homology search of query sequences aligned by a BLASTx against the Nr database.

\section{GO classification}

The GO classification based on sequence homology revealed that the 107,894 assembled unigenes were categorized into 56 functional groups (Figure 2). The three major categories were molecular function, biological processes, and cellular processes. In the 'biological process in level 2' category, unigenes related to 'metabolic processes' (31.92\%), 'cellular processes' (28.67\%), and 'biological regulation' (6.36\%) were predominant. 'Cell' (25.09\%), 'cell part' $(25.09 \%)$, and 'organelle' $(15.72 \%)$ were the most abundant class in the 'cellular component in level 2' category. In the 'molecular function in level 2' category, 'binding (45.87\%)', 'catalytic activities' (41.05\%), and 'transporter activity' $(41.05 \%)$ were the three largest groups. 

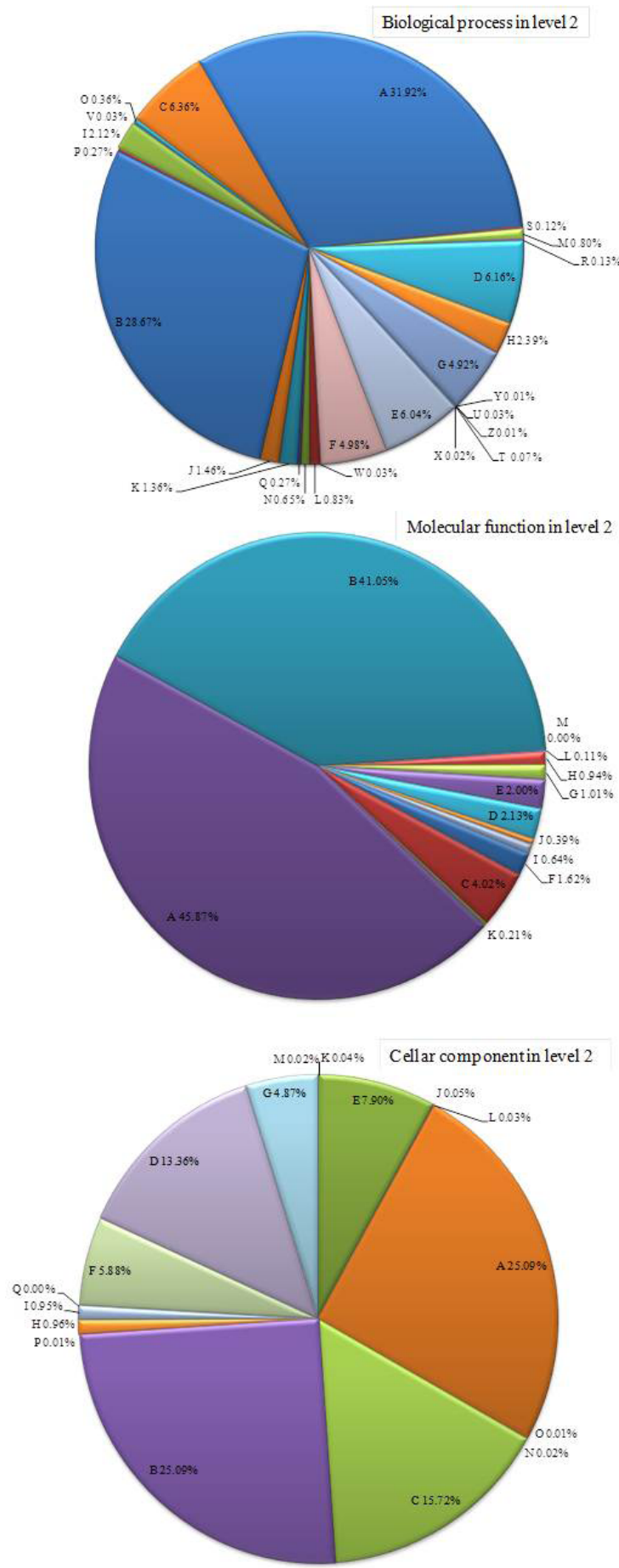

Figure 2. Gene Ontology classification of the assembled transcripts.
A, matabo lie pro cess

C. cellular process

D. regulation of biological process

$E$, responsato stimulus

F, localization

$\mathrm{G}$, sta blishment of localization

I, signaling

, multice llular organismal process

, developmental process

N, reproductive process

0 , negative re gulation of biolog gical proces

$P$, positiva regulation of biological procas

Q, growth

$S$, degthe sy temproces

1, cell proliferstion

V, viral raproductio

W, locomotion

$X$, biological a dhesion

Y, carbon utilization

\section{A, binding}

$\mathrm{B}$, catalytic activity

transporter activity

$D$, nucleic acid binding transcription

factor actirity

.

$\mathrm{G}$ moleculartran actucer ${ }^{\circ}$

$\mathrm{H}$. enzyme regulator a ctivity

$\mathrm{I}$, antioxidant activity

$\mathrm{K}$, protein binding transcription factor

activity

$\mathrm{L}$, nutrientreservoir activity

M, metallochaperone activity

\section{A, cell \\ B, cell part}

D. membran

E, membrane

$F$, macromolecular complex

$\mathrm{G}$, organelle part
$\mathrm{H}, \mathrm{mem}$ mrane-enclosed lume

I, extracellular region

cell junction

$\mathrm{K}$, extracellular region part

$\mathrm{L}$, cell junction

$\mathrm{M}$, extracellular matrix

$\mathrm{N}$, symplast

$O$, virion part

, virion

reellular matrix part

Genetics and Molecular Research 15 (3): gmr.15038599 


\section{COG classification}

In this analysis, 31,379 unigenes (29.08\%) were clustered into 25 functional categories using COG classification (Figure 3). The cluster for 'signal transduction mechanisms' (3863 unigenes, accounting for $12.31 \%$ ) was the largest group, followed by 'general function prediction only' $(3735,11.9 \%)$, 'post-translational modification, protein turnover, and chaperones' (3414, 10.88\%), and 'nuclear structure' (164, 0.52\%). 'Cell motility' (15, 0.04\%) was the smallest group.

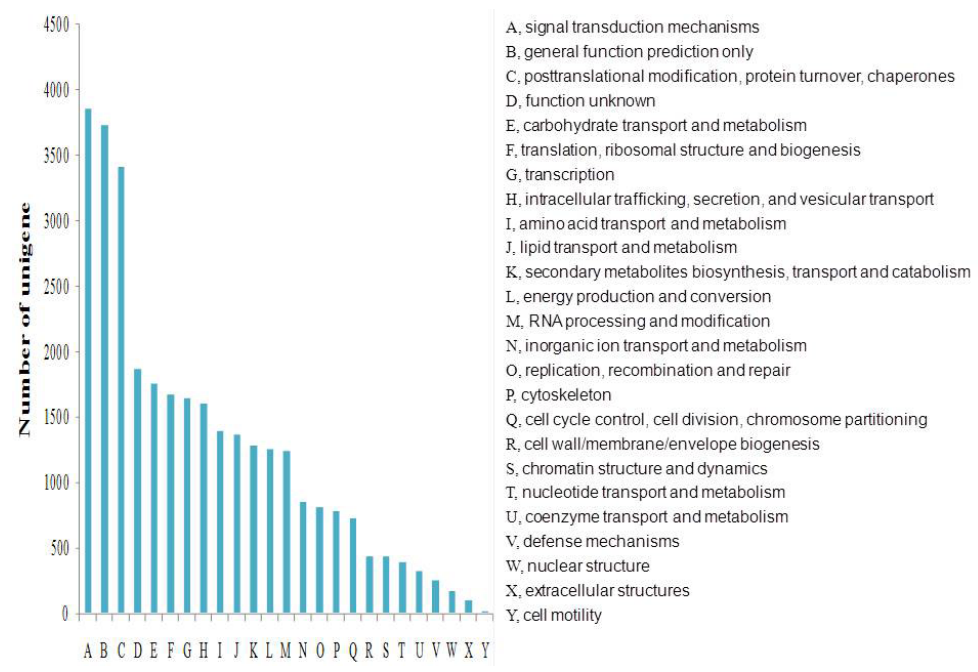

Figure 3. Distribution of genes in the transcriptome by COG functional classification.

\section{KEGG classification}

After KEGG analysis, 9945 DEGs were classified into 233 pathways, of which 26 key pathways were selected and counted carefully. The three dominant pathways were "metabolic pathways' (1282 unigenes, accounting for $12.89 \%$ ), 'biosynthesis of secondary metabolites' $(603,6.06 \%)$, and 'microbial metabolism in diverse environments' $(311,3.12 \%)$. We were interested in three pathways related to low-potassium; these pathways are 'plant hormone signal transduction' (151, 1.51\%), 'pyruvate metabolism' (59, 0.59\%), and 'ABC transporters' $(14,0.14 \%)$. The expression patterns of 15 DEGs involved in the pyruvate metabolism pathway were all up-regulated (Figure 4).

\section{EST-SSR detection and distribution}

In this study, 15,209 SSRs were found among the 107,824 unigenes. Among these SSRs, 15,209 microsatellites were included that contained di-, tri-, tetra-, penta-, hexa-, single, and mixed nucleotide repeats. An overview of the SSR results is summarized in Table 2. The highest abundance repeat motif was 'single SSR' (7762, 51.03\%), followed by 3721 'di-nucleotide SSRs' that accounted for $24.46 \%$. 'Penta-nucleotide SSR' $(26,0.17 \%)$ was the lowest group.

Genetics and Molecular Research 15 (3): gmr.15038599 


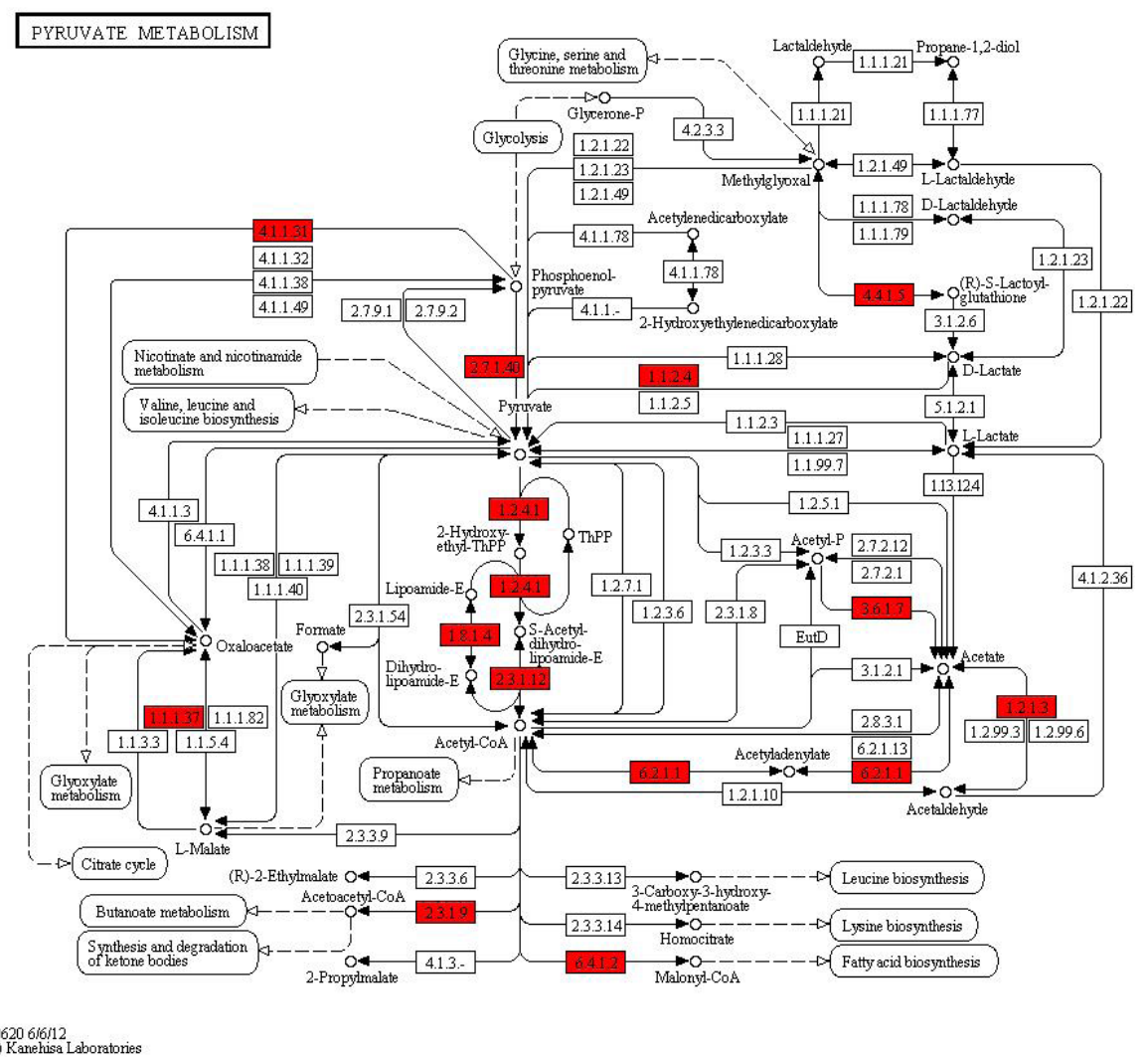

Figure 4. Expression pattern of genes involved in pyruvate metabolism. Red boxes in each column correspond to up-regulated enzymes. The heatmaps generated were colored to the corresponding DEGs from the KEGG database (map 00620).

\section{Table 2. Overview of the SSR statistic.}

\begin{tabular}{l|c|c}
\hline SSR statistic type & Number & Percentage (\%) \\
\hline Mixed SSR & 986.48 \\
\hline Single SSR & 7,762 & 51.03 \\
\hline Di-nucleotide SSR & 3,721 & 24.46 \\
\hline Tri-nucleotide SSR & 3,521 & 23.15 \\
\hline Tetra-nucleotide SSR & 123 & 0.80 \\
\hline Penta-nucleotide SSR & 26 & 0.17 \\
\hline Hexa-nucleotide SSR & 56 & 0.36 \\
\hline Total SSR & 15,209 & \\
\hline
\end{tabular}

\section{Differential gene expression and identification}

Differentially expressed genes between the CK and LK samples were analyzed by the fragments per kilobase of transcript per million fragments mapped (FPKM) method and $P$ value. An FPKM $\geq 2$ and $P$ value $\leq 0.01$ were the screening threshold values for the two samples. A total of 1034 DEGs were identified after low-potassium treatments for 3, 6, 12, and 24 h. Of the DEGs, 732 were up-regulated, and 302 were down-regulated (Figure 5).

Genetics and Molecular Research 15 (3): gmr.15038599 


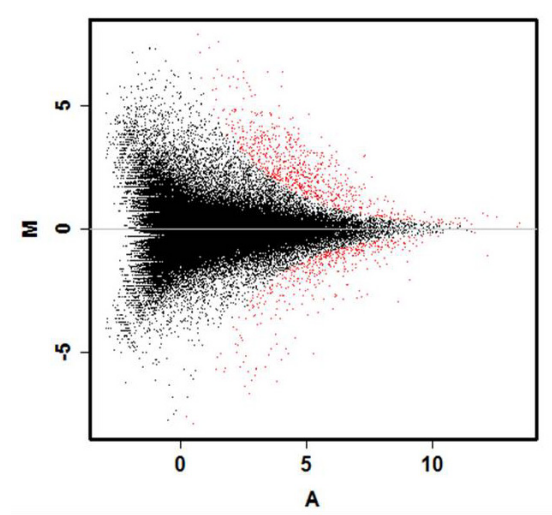

Figure 5. Identification of DEGs between $C K$ and LK samples. $M: y=\log _{2}$ (ratio of expression); $A: x=\log _{2}$ (intensity of expression). Red dots represent different genes.

To verify the RNA-seq data, 12 DEGs were randomly selected for qRT-PCR analysis, including DREB4 (contig_2186), ABA 8'-hydroxylase CYP707A1 (contig_2887), ethyleneresponsive transcription factor 4 (contig_3933), WRKY DNA-binding protein (contig_9447), brassinosteroid insensitive 1-associated receptor kinase 1 (contig_11451), osmotic stress-induced zinc-finger protein (contig_13923), calcium binding protein (contig_16053), regulator of gene silencing (contig_17001), membrane located receptor-like protein (contig_18779), metal ion binding protein (contig_19045), gibberellin-regulated protein 3 (contig_21298), and JA-induced WRKY protein (contig_26340). The qRT-PCR primer sequences are listed in Table 3.

Table 3. Unigene qRT-PCR primer sequences.

\begin{tabular}{l|l}
\hline Gene & Sequence (5'-3') \\
\hline contig_2186 F(DREB4) & CGGTCGCCTTCTGAATATCC \\
\hline contig_2186 R(DREB4) & TGATTCGGCTTGGAGGTTACC \\
\hline contig_9447 F(WRKY protein) & AGGTCAAGAGGAGATGATTTCGAT \\
\hline contig_9447 R(WRKY protein) & TCCTGGTGCTGATAAACCTTCA \\
\hline contig_2887 F(ABA 8'-hydroxylase) & CTGGGACAATGTTTCTGATCGA \\
\hline contig_2887 R(ABA 8'-hydroxylase) & CAAGGTGATTACCATGCTAAGTTGA \\
\hline contig_3933 F(ERF4) & GCCGGTTCTGCTCTTTGATT \\
\hline contig_3933 R(ERF4) & TGGTAAGGCTGAGGCCTGTT \\
\hline contig_18779 F(Receptor-like protein) & GTCGTCTACGTTATCAAGCACACA \\
\hline contig_18779 R(Receptor-like protein) & ATTTCTACATAACAGATTACGCTTCCAA \\
\hline contig_16053F(Calcium binding protein) & GGACCATAACGGCTTGATTTCT \\
\hline contig_16053 R(Calcium binding protein) & TGGTACAATTCTGGCCCAAAC \\
\hline contig_26340 F(WRKY protein) & TGTTAACATCTCCGTCAGCTTCTT \\
\hline contig_26340 R(WRKY protein) & TTATTGGGCTTGGAATAGATCACA \\
\hline contig_17001 F(Regulator of gene silencing) & ATGAAATGGAGGGGAGTGG \\
\hline contig_17001 R(Regulator of gene silencing) & CCTCCGTATCATAGCCTTGC \\
\hline contig_21298 F(Gibberellin-regulated protein) & CTGCCTACTTGCTCATGTCTCTTC \\
\hline contig_21298 R(Gibberellin-regulated protein) & CATATGGCAAGAGCCTCCTGTT \\
\hline contig_13923 F(zinc-finger protein) & ACAAGGCTTTTCCTACTGGTCAA \\
\hline contig_13923 R(zinc-finger protein) & CACCGAGTTTGCCTTCATAGTG \\
\hline contig_11451 F(receptor kinase) & TGGCTCAAAAAAGACTTGGATATATG \\
\hline contig_11451R(receptor kinase) & AACCACCCCCAAAAGAGACAA \\
\hline contig_19045 F(Metal ion binding protein) & GTTCTTTTCTTCCCCCGTCAT \\
\hline contig_19045 R(Metal ion binding protein) & CCAAGGCCTTAAAAATTGCTGTT \\
\hline
\end{tabular}

Genetics and Molecular Research 15 (3): gmr.15038599 
The results indicated that these gene expression levels were up-regulated after the qRT-PCR analysis, a result that is consistent with the RNA-seq data (Figure 6). However, the expression levels of four genes (i.e., ABA 8'-hydroxylase, ethylene-responsive transcription factor 4, WRKY DNA-binding protein, and calcium binding protein) calculated by qRT-PCR were higher than those generated by RNA-seq, a discrepancy potentially due to the higher sensitivity of qRT-PCR.

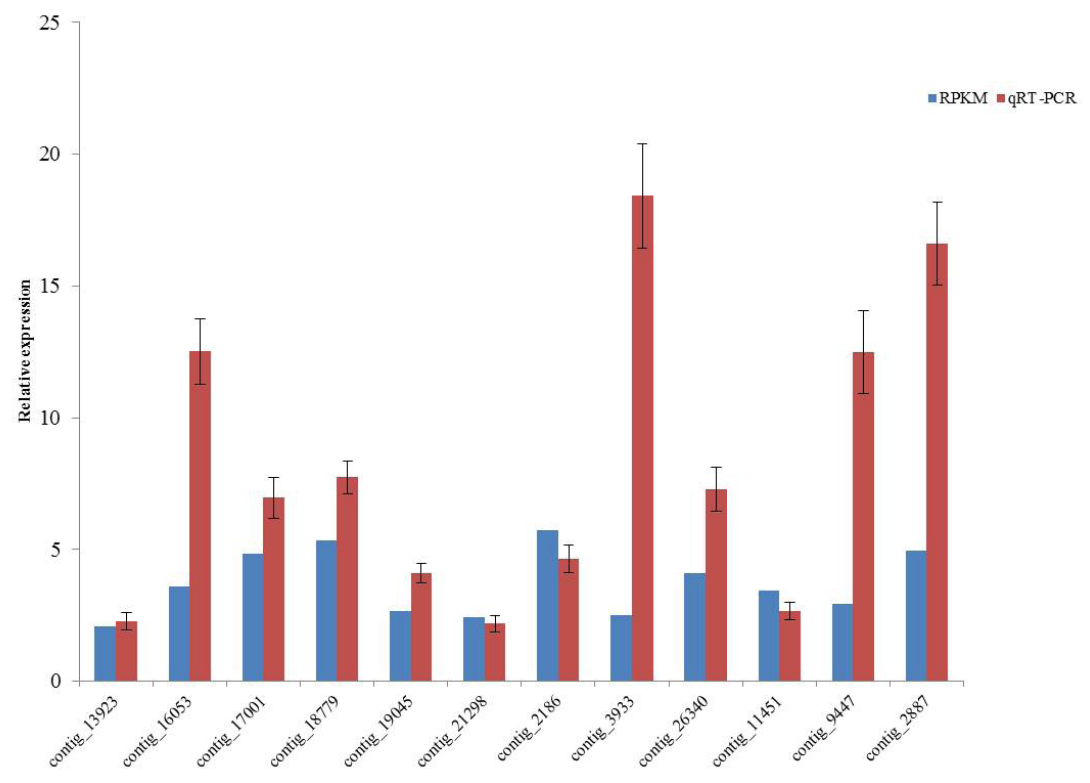

Figure 6. Confirmation of Solexa results by qRT-PCR.

\section{DEGs encoding transcription factors}

Transcription factors are involved in many abiotic stresses. In this study, 36 DEGs encoding transcription factors were found, including ethylene-responsive transcription factors (16), WRKY (8), DREB (5), GRAS (2), RAV (2), BZIP (1), HBP (1), and MYC (1). All 16 ethylene-responsive transcription factors had increased expression levels after low-potassium treatment. Similarly, 8 WRKY transcription factors were up-regulated, and their expression levels increased by at least 4.54-fold following low-potassium treatment. The expression level of 5 DREB transcription factors increased drastically from 8.30- to 14.64-fold. In total, 36 genes were up-regulated, and only BZIP was down-regulated (2.88-fold).

\section{DEGs encoding kinases, transporters and channel proteins}

Protein kinases are vital to plant cell transduction processes. Twenty kinases were identified, and among them 13 were protein kinases, 3 were MAPKs (mitogen-activated protein kinases), 2 were brassinosteroid insensitive 1-associated receptor kinases, and 2 were phosphoglycerate kinases (PGKs). Seventeen kinases had increased expression levels. Only one adenylate kinase and two phosphoglycerate kinases were down-regulated. We also found

Genetics and Molecular Research 15 (3): gmr.15038599 
6 up-regulated transporters, including $3 \mathrm{ABC}$ transporters, 1 hexose transporter, 1 sorbitol transporter, and 1 ATP/ADP transporter. In addition, 2 water channel proteins were identified and were down-regulated in response to low-potassium stress.

\section{DEGs related to hormone signaling and oxidase stress}

Hormone signaling is closely related to low-potassium stress. A total of 5 hormonerelated DEGs were found, including 2 auxin-repressed proteins, 2 jasmonic acid proteins, and 1 snakin. Among these DEGs, only snakin-2 (related to gibberellin) was down-regulated. A reactive oxygen species (ROS) signal can help a plant adapt to low-potassium conditions. Twenty-four DEGs involved in oxidase stress were identified; 9 genes were up-regulated, and 15 were down-regulated, including 16 peroxidases, 2 superoxide dismutases, 3 cytochrome P450s, and 3 oxidases.

\section{DISCUSSION}

Tobacco requires a large amount of potassium during its growth period. The potassium content is higher during the early stages of tobacco growth, but at later stages, a potassium efflux phenomenon is commonly produced after root senescence and topping. In our experiment, two cDNA libraries were generated from tobacco seedlings grown on MS medium and under low-potassium stress for 6,12 , and $24 \mathrm{~h}$ to determine the genes that are involved in lowpotassium stress. Thirty-five transcription factors were up-regulated, and only one, BZIP, was down-regulated. The expression levels of 16 ethylene-responsive transcription factors were up-regulated, and these factors can bind the GCC box (TAAGAGCCGCC) of target genes (Fujimoto et al., 2000). Two Ets2 repressor factors were involved in low-potassium stress (Shankar et al., 2013), so these genes may regulate target genes in pathways that respond to low-potassium levels in tobacco. NtWRKY3, NtWRKY6, and NtWRKY8 were previously reported to be involved in plant defense (Melanie et al., 2008; Nobuaki et al., 2011), and these three transcription factors were up-regulated under low-potassium stress. Their function will be studied in transgenic plants in the future.

The GRAS family is a class of plant-specific transcription factors that play essential roles in stress (Fode et al., 2008). Two GRAS genes were up-regulated by 2- to 4.7-fold. This finding suggests that these genes are positive regulators in response to low-potassium stress. Two NbMYC (bHLH) transcription factors were identified to be positive regulators in the jasmonate activation of nicotine biosynthesis (Kathleen et al., 2011). In this study, one MYC gene was up-regulated, indicating that tobacco MYC functions in low-potassium stress.

Calcium-dependent protein kinase (CDPK or CPK) conducts a calcium signal in a plant's response to various stimuli, including abiotic and biotic stresses (Schulz et al., 2013). Two CDPKs (CDPK8) were up-regulated in our study. NtCDPK2 and NtCDPK3 have been reported to respond to biotic or abiotic stress (Witte et al., 2010). OsSIK1 (receptor-like protein kinase) increased salt and drought tolerance in rice when over-expressed (Ouyang et al., 2010). Five receptor-like protein kinases were up-regulated from 5.84- to 6.12-fold. Thus, we hypothesized that these kinases play an important role in the adaptation to low-potassium stress in tobacco. Additionally, 3 mitogen-activated protein kinase kinase kinases (MAPKKK) had increased expression in our results. Recent studies showed that MAPK (mitogen-activated protein kinase) cascade systems are very important components of signal perception in the

Genetics and Molecular Research 15 (3): gmr.15038599 
signaling pathway of plants under abiotic stress (Sinha et al., 2011). Two brassinosteroidinsensitive 1-associated receptor kinases 1 ( $B A K 1)$ were up-regulated by at least 4.5 -fold after low-potassium stress. Previous research reported that BAK1 is a central regulator of brassinosteroid signaling (Heese et al., 2007). These results suggest that the brassinosteroid signal and low-potassium stress interact.

The absorption and uptake of $\mathrm{K}^{+}$in the plant cell is primarily performed by $\mathrm{K}^{+}$ transporters and $\mathrm{K}^{+}$channels (Ashley et al., 2006). However, in our transcriptomic analysis, none of the $\mathrm{K}^{+}$transporters or $\mathrm{K}^{+}$channels had a 2-fold change in gene expression. This result is similar to that obtained for rice (Shankar et al., 2013). Most $\mathrm{K}^{+}$transporters of wild barley increased after a $48 \mathrm{~h}$ low-potassium treatment (Zeng et al., 2014). Perhaps the transcription levels of $\mathrm{K}^{+}$transporters and $\mathrm{K}^{+}$channels were not significantly affected for short durations under low-potassium treatment. Among the 6 transporters, $3 \mathrm{ABC}$ transporters were up-regulated. In Arabidopsis, the $\mathrm{ABC}$ transporters are involved in $\mathrm{ABA}$ and the drought pathway (Kang et al., 2010; Kuromori et al., 2011). The sorbitol transporter expression level was increased 3-fold, suggesting that it responds to low-potassium stress in tobacco. Li et al. (2012) reported that three sorbitol transporter genes in apples were involved in drought stress. Two water channel proteins were down-regulated. The over-expression of AqpL1 (water channel protein) in tobacco greatly increased the osmotic water permeability of leaf protoplasts (Ding et al., 2004), but the expression level of two aquaporin genes (CsPIP1; 2 and $C s P I P 2 ; 4)$ from cucumber decreased after PEG and $\mathrm{NaCl}$ treatment for 2 and $24 \mathrm{~h}$ of treatment (Qian et al., 2014), suggesting that water channel proteins in different plants have different regulatory mechanisms.

The auxin-repressed protein is a negative regulator of auxin. When the auxin content is high, the gene expression level is low, and the plant will grow (Park and Han, 2003). In the present study, 2 auxin-repressed proteins were up-regulated, demonstrating their importance in plant cells, but their mechanism of action remains to be studied. Jasmonic acid is a vital plant hormone with a close relationship to biotic and abiotic resistance. Two genes related to jasmonic acid were up-regulated by at least 4.5 -fold. Jasmonic acid and auxin affect root growth through a common interaction (Sun et al., 2011; Chen et al., 2011). This report is the first to indicate that jasmonic acid is related to low-potassium stress. A gene annotated as snakin-2, which responds to gibberellin, was down-regulated by 2.68fold. In potato, Snakin-2 was induced by ABA and depressed by GA (Marta et al., 2002). GA can improve the auxin content, suggesting that plant hormones interact in a complex network that responds to low-potassium stress.

ROS act as important signaling molecules, especially in response to potassium starvation (Bhattacharjee, 2005; Shin et al., 2005). The expression level of many genes related to ROS production and detoxification changed in this study, and this result is consistent with previous reports (Wang et al., 2012; Shankar et al., 2013). Among the genes, 3 cytochrome P450s were up-regulated, and P450 can regulate auxin synthesis in Arabidopsis (Bak et al., 2001). Thus, we hypothesize that P450 functions in potassium deficiency stress by modulating root growth to some extent. Two superoxide dismutases were up-regulated by at least 3-fold; thus, a higher level of superoxide dismutases could protect cells against membrane peroxidation after low-potassium stress. In this study, transcription factor, protein kinase, transporter, plant hormone signaling molecule, and oxidase stress factor genes in tobacco seedlings constituted an important gene-regulatory network under early low-potassium stress (Figure 7). Further research using over-expression and RNAi technology should focus on the functions of these genes.

Genetics and Molecular Research 15 (3): gmr.15038599 


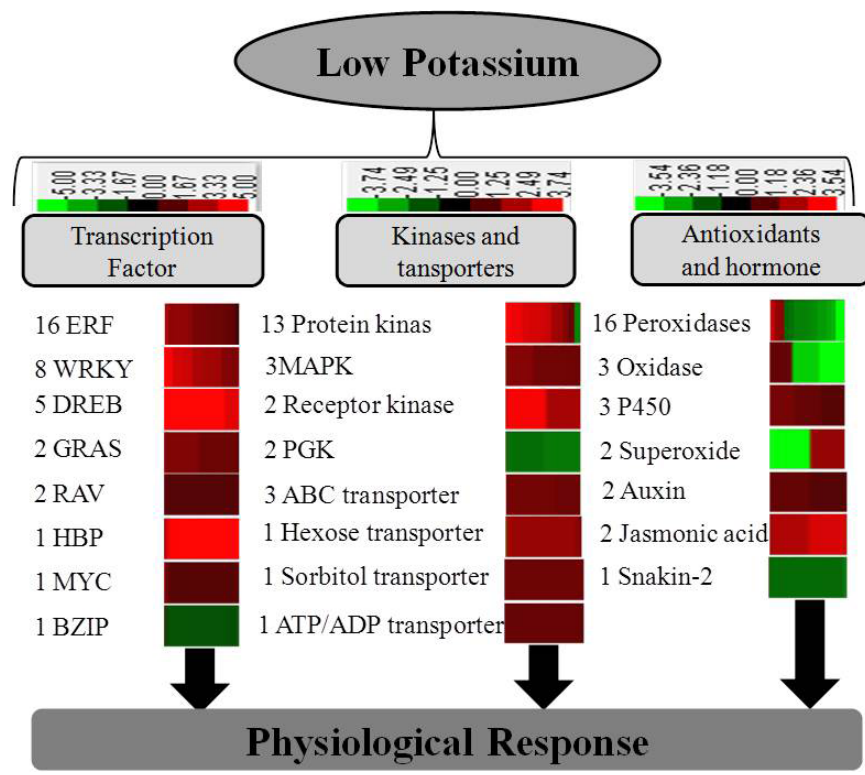

Figure 7. Expression pattern of genes involved in low-potassium stress. Red boxes correspond to up-regulated genes, green boxes correspond to down-regulated genes, and numbers preceding gene names correspond to gene number.

\section{Conflicts of interest}

The authors declare no conflict of interest.

\section{ACKNOWLEDGMENTS}

Research supported by the State Key Laboratory of Plant Physiology and Biochemistry of China (SKLPPBKF 1505 and SKLPPBKF 1506).

\section{REFERENCES}

Ashley MK, Grant M and Grabov A (2006). Plant responses to potassium deficiencies: a role for potassium transport proteins. J. Exp. Bot. 57: 425-436.

Bak S, Tax FE, Feldmann KA, Galbraith DW, et al. (2001). CYP83B1, a cytochrome P450 at the metabolic branch point in auxin and indole glucosinolate biosynthesis in Arabidopsis. Plant Cell 13: 101-111.http://dx.doi.org/10.1105/ tpc.13.1.101

Bañuelos MA, Garciadeblas B, Cubero B and Rodríguez NA (2002). Inventory and functional characterization of the HAK potassium transporters of rice. Plant Physiol. 130: 784-795.http://dx.doi.org/10.1104/pp.007781

Bhattacharjee S (2005). Reactive oxygen species and oxidative burst: Roles in stress, senescence and signal transduction in plants. Curr. Sci. India 89: 7-10.

Buschmann PH, Vaidyanathan R, Gassmann W and Schroeder JI (2000). Enhancement of $\mathrm{Na}^{+}$uptake currents, timedependent inward-rectifying $\mathrm{K}^{+}$channel currents, and $\mathrm{K}^{+}$channel transcripts by $\mathrm{K}^{+}$starvation in wheat root cells. Plant Physiol. 122: 1387-1397. http://dx.doi.org/10.1104/pp.122.4.1387

Chaplin JR (1980). Production factors affecting chemical compounds of the tobacco leaf. Rec. Adv. Tob. 6: 3-63.

Chen Q, Sun J, Zhai Q, Zhou W, et al. (2011). The basic helix-loop-helix transcription factor MYC2 directly represses PLETHORA expression during jasmonate-mediated modulation of the root stem cell niche in Arabidopsis. Plant Cell 23: 3335-3352. http://dx.doi.org/10.1105/tpc.111.089870

Genetics and Molecular Research 15 (3): gmr.15038599 
Ding X, Iwasaki IY and Kitagawa Y (2004). Over expression of a lily PIP1 gene in tobacco increased the osmotic water permeability of leaf cells. Plant Cell Environ. 27: 177-186. http://dx.doi.org/10.1046/j.0016-8025.2003.01130.x

Fode B, Siemsen T, Thurow C, Weigel R, et al. (2008). The Arabidopsis GRAS protein SCL14 interacts with class II TGA transcript ion factors and is essential for the activation of stress inducible promoters. Plant Cell 120: 3122- 3135. http://dx.doi.org/10.1105/tpc. 108.058974

Fujimoto SY, Masaru OM, Usui A, Shinshi H, et al. (2000). Arabidopsis ethylene-responsive element binding factors act as transcriptional activators or repressors of GCC boxmediated gene expression. Plant Cell 3: 393-404.http://dx.doi. org/10.1105/tpc.12.3.393

Gierth M, Mäser P and Schroeder J (2005). The potassium transporter AtHAK5 functions in $\mathrm{K}^{+}$deprivation-induced highaffinity $\mathrm{K}^{+}$uptake and $\mathrm{AKT} 1 \mathrm{~K}^{+}$channel contributionto $\mathrm{K}^{+}$uptake kinetics in Arabidopsis roots. Plant Physiol. 137: 1105-1114.

Heese A, Hann DR, Gimenez-Ibanez S, Jones AME, et al. (2007). The receptor-like kinase SERK3/BAK1 is a central regulator of innate immunity in plants. P. Natl. Acad. Sci. USA. 29: 12217-12222. http://dx.doi.org/10.1073/ pnas.0705306104

Held K, Pascaud F, Eckert C, Gajdanowicz P, et al. (2011). Calcium-dependent modulation and plasma membrane targeting of the AKT2 potassium channel by the CBL4/CIPK6 calcium sensor/protein kinase complex. Cell Res. 21: 1116-1130. http://dx.doi.org/10.1038/cr.2011.50

Kang J, Hwang JU, Lee M, Kim YY, et al. (2010). PDR-type ABC transporter mediates cellular uptake of the phytohormone abscisic acid. P. Natl. Acad. Sci. USA. 5: 2355-2360. http://dx.doi.org/10.1073/pnas.0909222107

Kathleen DB, Sofie T, Laurens P, Robin VB, et al. (2011). Apetala2/ethylene response factor and basic helixloophelix tobacco transcription factors cooperatively mediate jasmonate-elicited nicotine biosynthesis. Plant J. 66: 1053-1065. http://dx.doi.org/10.1111/j.1365-313X.2011.04566.x

Kuromori T, Sugimoto E and Shinozaki K (2011). Arabidopsis mutants of At ABCG22, an ABC transporter gene, increase water transpiration and drought susceptibility. Plant J. 5: 885-894. http://dx.doi.org/10.1111/j.1365$\underline{313 X .2011 .04641 . \mathrm{X}}$

Li F, Lei H J, Zhao X J, Tian RR, et al. (2012). Characterization of three sorbitol transporter genes in micropropagated apple plants grown under drought stress. Plant Mol. Biol. Rep. 30: 123-130. http://dx.doi.org/10.1007/s11105-011$\underline{0323-4}$

Liu LL, Ren HM, Chen LQ, WangY, et al. (2013). A protein kinase CIPK9 interacts with calcium sensor CBL3 and regulates $\mathrm{K}^{+}$homeostasis under low-K $\mathrm{K}^{+}$stress in Arabidopsis. Plant Physiol. 161: 266-277.http://dx.doi.org/10.1104/ pp.112.206896

Lu LM, Chen Y, Lu L, Lu YF, et al. (2015). Transcriptome analysis reveals dynamic changes in the gene expression of tobacco seedlings under low potassium stress. J. Genet. 94: 532-541.http://dx.doi.org/10.1007/s12041-015-0532-y

Marta BL, Ana S, Manuel M, Gemma L, et al. (2002). Snakin-2, an antimicrobial peptide from potato whose gene is locally induced by wounding and responds to pathogen infection. Plant Physiol. 128: 951-961.http://dx.doi.org/10.1104/ pp. 010685

Mortazavi A, Williams BA, McCue K, Schaeffer L, et al. (2008). Mapping and quantifying mammalian transcriptomes by RNA-Seq. Nat. Methods. 5: 621-628. http://dx.doi.org/10.1038/nmeth.1226

Melanie S, Nan Q, Ivan G and Ian TB (2008). Induced plant defenses in the natural environment: Nicotiana attenuata WRKY3 and WRKY6 coordinate responses to herbivory. Plant Cell 20: 1984-2000. http://dx.doi.org/10.1105/ tpc.108.058594

Nobuaki I, Reiko Y, Miki Y, Shinpei K, et al. (2011). Phosphorylation of the Nicotiana benthamiana WRKY8 transcription factor by MAPK functions in the defense fesponse. Plant Cell 23: 1153-1170.http://dx.doi.org/10.1105/ tpc. 110.081794

Ouyang SQ, Liu YF, Liu P, Lei G, et al. (2010). Receptor-like kinase OsSIK1 improves drought and salt stress tolerance in rice (Oryza sativa) plants. Plant J. 62: 316-329. http://dx.doi.org/10.1111/j.1365-313X.2010.04146.x

Park S and Han KH (2003). An auxin-repressed gene (RpARP) from black locust (Robinia pseudoacacia) is post transcriptionally regulated and negatively associated with shoot elongation. Tree Physiol. 12: 815-823.http://dx.doi. org/10.1093/treephys/23.12.815

Postnikova OA, Shao J and Nemchinov LG (2013). Analysis of the alfalfa root transcriptome in response to salinity stress. Plant Cell Physiol. 54: 1041-1055.http://dx.doi.org/10.1093/pcp/pct056

Qian ZJ, Song JJ, Chaumont F and Ye Q (2014). Differential responses of plasma membrane aquaporins in mediating water transport of cucumber seedlings under osmotic and salt stresses. Plant Cell Environ. 38: 461-473. http://dx.doi. org $/ 10.1111 /$ pce. 12319

Schulz P, Herde M and Romeis T (2013). Calcium-dependent protein kinases: hubs in plant stress signaling and development. Plant Physiol. 163: 523-530. http://dx.doi.org/10.1104/pp.113.222539

Genetics and Molecular Research 15 (3): gmr.15038599 
Shankar A, Singh A, Kanwar P, Srivastava AK, et al. (2013). Gene expression analysis of rice seedling under potassium deprivation reveals major changes in metabolism and signaling components. PLOS One 7: e70321 http://dx.doi. org/10.1371/journal.pone.0070321

Shin R, Berg RH and Schachtman DP (2005). Reactive oxygen species and root hairs in Arabidopsis root response to nitrogen, phosphorus and potassium deficiency. Plant Cell Physiol. 46: 1350-1357. http://dx.doi.org/10.1093/pcp/ pci145

Sinha AK, Jaggi M, Raghuram B and Tuteja N (2011). Mitogen-activated protein kinase signaling in plants under abiotic stress. Plant Signaling Behav. 6: 196-203.http://dx.doi.org/10.4161/psb.6.2.14701

Sun J, Chen Q, Qi L, Jiang H, et al. (2011). Jasmonate modulates endocytosis and plasma membrane accumulation of the Arabidopsis PIN2 protein. New Phytol. 191: 360-375.http://dx.doi.org/10.1111/j.1469-8137.2011.03713.x

Vanverk MC, Hickman R, Pieterse CM and Van WS (2013). RNA-Seq: revelation of the messengers. Trends Plant Sci. 18: 175-179. http://dx.doi.org/10.1016/j.tplants.2013.02.001

Very AA and Sentenac H (2003). Molecular mechanisms and regulation of $\mathrm{K}^{+}$transport in higher plants. Annu. Rev. Plant Biol. 54: 575-603.http://dx.doi.org/10.1146/annurev.arplant.54.031902.134831

Wang C, Chen HF, Hao QN, Sha HA, et al. (2012). Transcript profile of the response of two soybean genotypes to potassium deficiency. PLOS One 7: e39856. http://dx.doi.org/10.1371/journal.pone.0039856

Wang L, Feng Z, Wang X, Wang X, et al. (2010). DEGseq: an R package foridentifying differentially expressed genes from RNA-seq data. Bioinformatics 26: 136-138. http://dx.doi.org/10.1093/bioinformatics/btp612

Ward JM, Mser P and Schroeder JI (2009). Plant ion channels: gene families, physiology, and functional genomics analyses. Annu. Rev. Physiol. 71: 59-82. http://dx.doi.org/10.1146/annurev.physiol.010908.163204

Witte CP, Keinath N, Dubiella U, Demoulière R, et al. (2010). Tobacco calcium-dependent protein kinases are differentially phosphorylated in vivo as part of a kinase cascade that regulates stress response. J. Biol. Chem. 13: 9740-9748. http:// dx.doi.org/10.1074/jbc.M109.052126

Xu J, Li HD, Chen LQ, Wang Y, et al. (2006). A protein kinase, interacting with two calcineurin B-like proteins, regulates $\mathrm{K}^{+}$transporter AKT1 in Arabidopsis. Cell 125: 1347-1360.http://dx.doi.org/10.1016/j.cell.2006.06.011

Yamamoto T, Umemura S and Kaneko H (1990). Effect of exogenous potassium on the reduction in tar nicotine and carbon monoxide deliveries in the mainstream smoke of cigarettes. Beitr. Tabakforsch. Int. 14: 379-385.

Ye J, Fang L, Zheng H, Zhang Y, et al. (2006). WEGO: a web tool for plotting GO annotations. Nucleic Acids Res. 34: W293-W297.http://dx.doi.org/10.1093/nar/gk1031

Zeng JB, He XY, Wu DZ, Zhu B, et al. (2014). Comparative transcriptome profiling of two Tibetan wild barley genotypes in response to low potassium. PLOS One 9:e100567.http://dx.doi.org/10.1371/journal.pone.0100567

Genetics and Molecular Research 15 (3): gmr.15038599 